\begin{tabular}{|c|c|c|}
\hline $\begin{array}{l}\text { PKS } \\
\text { PUBLIC } \\
\text { KNDOLEDGE } \\
\text { PROJECT }\end{array}$ & $\begin{array}{c}\text { REVISTA DE GEOGRAFIA } \\
\text { (RECIFE) } \\
\text { http://www.revista.ufpe.br/revistageografia }\end{array}$ & $\begin{array}{l}\text { OJS } \\
\text { OPEN } \\
\text { JOUNAL } \\
\text { SYSTEMS }\end{array}$ \\
\hline
\end{tabular}

\title{
UM QUILOMBO EM MOVIMENTO: TERRITORIALIDADE E ATUAÇÃO POLÍTICA DA COMUNIDADE DO ROSA, MACAPÁ (AP)
}

\author{
David Junior de Souza Silva ${ }^{1}$, Eguimar Felicio Chaveiro ${ }^{2}$
}

\begin{abstract}
${ }^{1}$ Professor do Departamento de Filosofia e Ciências Humanas da Universidade Federal do Amapá DFCH/UNIFAP. Doutorando em Geografia pelo Instituto de Estudos Socioambientais da Universidade Federal de Goiás - IESA/UFG. E-mail: davi_rosendo@live.com

${ }^{2}$ Professor do Programa de Pós-Graduação em Geografia do Instituto de Estudos Socioambientais da Universidade Federal de Goiás - IESA/UFGE-mail: eguimar@hotmail.com
\end{abstract}

Artigo recebido em 19/09/2018 e aceito em 07/12/2018

\begin{abstract}
RESUMO
Este artigo tem como objetivo a abordagem da territorialidade da comunidade remanescente quilombola do Rosa, localizada na zona rural do município de Macapá, estado do Amapá. A problemática está na análise da transformação da territorialidade do Rosa iniciada no seu processo de autoidentificação como comunidade remanescente quilombola. A metodologia de pesquisa consiste em etnografia junto à comunidade, realizada ao longo de 2017. O conceito recrutado para subsidiar a análise é o de territorialidade, tal como desenvolvido por Alex Ratts. A transformação identitária vivida pelo grupo no processo de reconhecimento como quilombola implica constitutivamente uma alteração na territorialidade. A razão de ser desta territorialidade é a garantia efetiva da cidadania étnica da comunidade. Como resultados identificamos que na territorialidade do Rosa há alianças de caráter político propriamente dito, de caráter festivo-emotivo-identitário, de caráter materialeconômico. A formação destas alianças dá condição de possibilidade para ações políticas de maior envergadura, maior força e maior impacto político.
\end{abstract}

Palavras-chave: Quilombo do Rosa; territorialidade; direitos étnicos; Amazônia.

\section{A KILOMBO IN MOVEMENT: TERRITORIALITY AND POLITICAL ACTION OF THE COMMUNITY OF ROSA, MACAPÁ (AP)}

\begin{abstract}
This article aims to approach the territoriality of the remaining quilombola community of Rosa, located in the rural area of the city of Macapá, Amapá state, in brazilian Amazon. The problematic is in the analysis of the transformation of the territoriality of the Rosa initiated in its process of self-identification as a remaining quilombola community. The methodology of the research consists of ethnography with the community, carried out throughout 2017. The concept recruited to subsidize the analysis is that of territoriality, as developed by Alex Ratts. The identity transformation experienced by the group in the recognition process as a quilombola constitutively implies a change in territoriality. The raison d'être of this territoriality is the effective guarantee of the ethnic citizenship of the community. As results, we identify that in the territoriality of Rosa there are alliances of a political character, festive-emotive-identity, of a material-economic character. The formation of these alliances gives a condition of possibility for larger political actions, greater strength and greater political impact.
\end{abstract}

Keywords: Rosa Kilombo; territoriality; ethnics rights; Amazon. 


\section{INTRODUÇÃO}

Este artigo tem como objetivo a abordagem da territorialidade da comunidade remanescente quilombola do Rosa. O quilombo do Rosa localiza-se na zona rural do município de Macapá, a $20 \mathrm{~km}$ da sede administrativa, no sentido da rodovia que liga Macapá a Porto Grande.

Figura 1 - Localização do Rosa no Estado do Amapá e no Município de Macapá

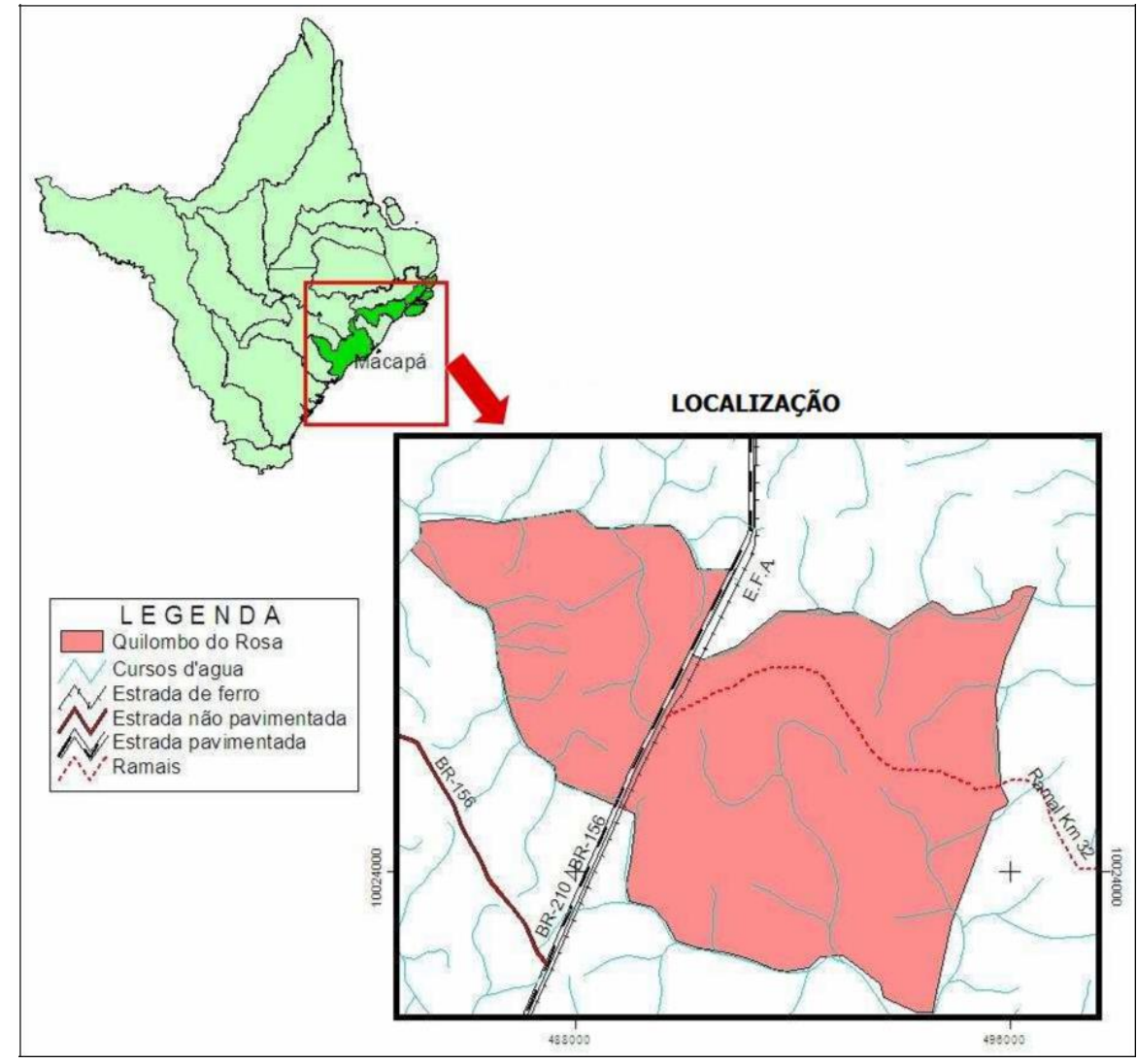

Fonte: Mapa elaborado por Edmilson M. Batista. Geógrafo - SR-21/INCRA, 2007. Citado de Alba Figueroa (2007).

Segundo pesquisa coordenada por Superti e Silva (2017), o perímetro da comunidade é assim situado:

Seu perímetro é constituído, em sua maior parte, por limites naturais, como igarapés e ressacas. Sua parte central situa-se num divisor de águas, que foi aproveitado para o traçado da estrada e da via férrea que liga Macapá ao Município de Serra do Navio. Registre-se que parte da área está sobreposta à APA do Curiaú, uma unidade de conservação de Uso Sustentável. A área de sobreposição com a APA é a parte do Rosa, que configura a vertente do lago Curiaú: a leste da BR-210/156 e ao sul do Ramal da Pedreira.

A comunidade foi fundada por Josino Valério de Azevedo Coutinho e sua esposa, Marcelina, em 22 de fevereiro 1902. Formado hoje por 23 famílias, descendentes do casal fundador, o Rosa hoje representa-se pela Associação dos Moradores e Produtores do 
Quilombo do Rosa (AMPQR), fundada em 2003. A comunidade iniciou seu processo de autoidentificação como quilombola e de titulação de seu território no ano de 2003.

As reflexões aqui desenvolvidas assentam-se nas transformações identitárias, culturais e territoriais vividas pela comunidade a partir da sua autoidentificação como quilombola. Este momento, desencadeado no início do século XXI, é assim resumido por Almeida e Marin (2014, p.3):

\begin{abstract}
No século XXI, inicia, precisamente no dia 24 de junho de 2004, o pedido de titulação coletiva no INCRA SR-21. Em 2008, foi concluído, pelo INCRA, o Relatório Técnico de Identificação e Delimitação do Território da Comunidade de Remanescentes de Quilombo do Rosa. O INCRA publicou, no Diário Oficial da União, o edital relativo ao Relatório, em 29 de abril de 2010. A equipe do INCRA analisou as Contestações recebidas, que não foram acatadas.
\end{abstract}

Foi publicada a portaria de titulação do território por parte do poder público em 21 de dezembro de 2016. Todavia, a posse definitiva do território ainda não lhes foi assegurada, até que o INCRA realize a desintrusão completa dos intrusos no território.

A transformação identitária vivida pelo grupo no processo de reconhecimento como quilombola implica constitutivamente uma alteração na territorialidade, porque são dependentes uma da outra. À medida em que, conforme os pressupostos e conclusões de Ratts (1996) existe uma relação interna entre "memória, território e auto-imagem” (p. 97), a transformação em um dos elementos da tríade implica transformação necessária nos outros dois. Destarte, nunca se tratam de uma transformação estritamente identitária os processos de autoidentificação como quilombola das comunidades negras rurais.

Quando o autorreconhecimento identitário do grupo muda, sua autoimagem, sua memória, seu patrimônio cultural e sua territorialidade sofrem transformações também. É sobre as transformações desta última dimensão, oriundas do movimento de autoidentificação da comunidade do Rosa.

Além desta transformação específica vivenciada pelo quilombo do Rosa, a problemática aqui apresentada assenta-se no fato mais geral de que as "comunidades negras rurais estabelecem alianças com variados segmentos locais, regionais e nacionais" (RATTS, 2000, p. 318).

Neste trabalho, ao tratar da territorialidade de uma comunidade étnica, estaremos nos inserindo em um estudo de interface entre Geografia e Antropologia que já vem sendo realizado por Alecsandro Ratts, trabalho definido pelo autor como uma "abordagem geográfica da etnicidade e de sua espacialidade" (RATTS, 2003, p. 29).

$\begin{array}{lcc}\text { Souza Silva e Chaveiro, } 2018 & 119\end{array}$


O objetivo do trabalho, assim, considerando a acepção de territorialidade aqui adotada, é problematizar as múltiplas relações sociais desenvolvidas pela comunidade com atores em torno, sejam elas visando centralmente a sociabilidade, sejam alianças com objetivos políticos; ou seja, analisar tanto sua natureza, quanto seus modos de constituição históricos.

A metodologia consiste de etnografia junto à comunidade, realizada desde o início de 2017, acompanhada de leitura dos documentos relativos à comunidade, como portaria de titulação e laudo antropológico.

A técnica etnográfica foi utilizada pelo seu potencial de levantar os diversos elementos que compõem a experiência da comunidade e identificar o significado de cada um destes elementos em seu universo.

A vertente etnográfica utilizada aqui é a proposta por Marshall Sahlins (1993), que foi porque dos métodos etnográficos é o que propõe, como campo de investigação etnográfica, colocar em evidência a transformação cultural vivida pelos povos nativos na crescentemente complexa relação que vivem com os Estados-Nação.

Não se trata de reificar uma cultura ou modo de vida, mas exatamente de identificar as autênticas transformações sociais e culturais que vivem os povos nativos, sempre a partir de seu ethos, seu ethnos e sua compreensão dos processos sociais e das intenções dos atores sociais com os quais se relaciona. Uma das bases epistemológicas do método etnográfico de Sahlins é o reconhecimento da autenticidade das transformações culturais que vivem os povos nativos e a escolha epistemológica pelo enfoque a esses processos como forma privilegiada de compreensão da cultura.: "The very ways societies change have their own authenticity, so that global modernity is often reproduced as local diversity" (SAHLINS, op. cit., p. 2).

\section{TERRITORIALIZAÇÃO E TERRITORIALIDADE}

Nesta seção trataremos de forma introdutória dos conceitos de territorialização e territorialidade, como preparação para a discussão central da seção: a inter-relação entre territorialização e territorialidade no processo protagonizado pelo Rosa neste início de século.

Segundo Marcelo Lopes de Souza (2013, p. 102), a territorialização é "um processo que envolve o exercício de relações de poder e a projeção dessas relações no espaço". Para o caso do Rosa, este processo implica a autonomia sobre seu território, face às ameaças reais das indústrias de madeira, da minerção e do agronegócio monocultor, bem como do turismo e da rodovia que corta as terras da comunidade, e a possibilidade de expressar sua própria 
identidade étnica como grupo em seu território comunitário; outrossim, a conquista de elementos materiais fundamentais para a vida do grupo.

Tal definição de territorialização coaduna com sua concepção de território: conforme Souza (2013, p 88) “o que 'define' o território é, em primeiríssimo lugar, o poder. Ou, em outras palavras, o que determina o 'perfil' do conceito é a dimensão política das relações sociais, compreendendo essa dimensão no sentido amplo de o político, e não no sentido de a política". A limitação de sua conceituação está em conferir caráter secundário à cultura ou identidade cultural na formação do território e, portanto, da espacialidade de um grupo.

Diferentemente das abordagens que definem o território unicamente pelo poder (como Souza, 2013), Rogério Haesbaert compreende o território como um fato simultânea e indissociavelmente político e simbólico. Nas palavras do autor, o território "diz respeito tanto ao poder no sentido mais concreto, de dominação, quanto ao poder no sentido mais simbólico, de apropriação.” (HAESBAERT, 2005, p. 6774); é composto, pois, de duas dimensões distinguíveis e constitutivas.

Em outra obra, o autor desenvolve o conceito afirmando que o território "desdobra-se de um continuum que vai da dominação político-econômica mais 'concreta' e 'funcional' à apropriação mais subjetiva e/ou cultural-simbólica'." (HAESBAERT, 2004, pp. 95-96). A indissociabilidade do elemento político e do elemento simbólico aqui é ainda mais evidente e permanece constitutiva. A territorialidade, como decorrência da categoria anterior, incorpora uma dimensão estritamente política, mas também se refere às relações econômicas e culturais próprias de cada sociedade ou grupo.

O processo de territorialização, para o autor, malgrado possa ser tipificado segundo quatro grandes objetivos (HAESBAERT, 2005, p. 6778), trata-se de um processo conjunto de apropriação simbólica e domínio político do espaço, operando segundo a cultura e a movimentação política do grupo em questão. É com esta concepção de território que faremos a análise dos processos vividos pelo Rosa da Pedreira.

No período analisado, o Rosa inicia um processo novo de territorialização. A partir da sua autoidentificação como comunidade remanescente quilombola, o grupo inicia a luta pela efetivação de seus direitos territoriais. Este processo, novo na história do grupo, indica uma nova territorialização, com o acréscimo da diferença qualitativa de ser ainda uma territorialização calcada no elemento étnico da tradição do grupo - uma tradição cultural específica, que localmente se designa por afroamapaense. 
Temos em vista aqui que uma nova territorialização não é apenas um lançar de forma menos ou mais concreta, ou menos ou mais intensa, com maior força jurídica, relações de poder sobre um dado local; uma nova territorialização significa isto, porém significa também uma territorialidade com novo conteúdo. Territorialização não é apenas medida em termos de graus de dominação do espaço; é também nas diferentes formas ou qualidades desta dominação; nos diferentes conteúdos significativos atribuídos ao espaço, que materializam sua dominação, e por intermédio dos quais se realiza o vínculo do grupo com o território. Uma mesma dominação do espaço, com conteúdo novo, inclusive no que concerne a direitos, implica uma nova territorialização.

Os contextos pluriétnicos de contato, todavia, são delicados, sobretudo, no que concerne à efetivação dos direitos dos povos tradicionais, mesmo aqueles garantidos em lei e na Constituição. Destarte, cada comunidade tradicional precisava se relacionar com a sociedade nacional, com o Estado e com atores da sociedade civil desta sociedade, aliados e defensores de seus direitos, no sentido de fortalecer-se politicamente, se fazer visível, e assim ter seus direitos étnicos e territoriais efetivados, concretizando um novo processo de territorialização. Assim a formação de alianças, como um dos aspectos - aquele propriamente político - da territorialidade do grupo, é fundamental nas situações de contato para o processo de territorialização; por isso ambos não serão analisados em sua mútua relação aqui.

A essas relações de aliança entre povos tradicionais e setores do Estado e atores da sociedade civil nacionais chamaremos aqui territorialidade. Veremos como a territorialidade é fundamental para a territorialização de um grupo em contexto multiétnico de contato.

A acepção primeira do termo territorialidade remete ao vínculo de um dado grupo social com o solo, com o substrato material no qual vive. Neste trabalho daremos continuidade à reflexão desenvolvida por Alecsandro Ratts, que amplia o significado de territorialidade para além dos vínculos que um grupo social desenvolve com o solo.

Conforme o autor, a "relação entre comunidade e espaço, em um contexto pluriétnico de intenso contato, não se resume aos limites visíveis das terras ocupadas”. (RATTS, 1996, p. 101). Isto é, a territorialidade diz respeito a relações com o solo que vão além dos limites das terras ocupadas; isto inclui relações de afinidade - e mesmo de não-afinidade - com atores situados fora da comunidade, porém cujo escopo de ação social influencia direta ou eventualmente a vida da comunidade.

Com base na acepção elaborada por Ratts, queremos desenvolver aqui o conceito de territorialidade como dizendo respeito a todas as relações sociais estabelecidas por um grupo 
com os atores sociais que o circundam, tendo por finalidade diretamente a defesa do território ou não. Para fundamentar sua noção de territorialidade, Ratts dialoga com o geógrafo Claude Raffestin, o qual afirma que a "territorialidade não consiste numa simples ligação com o espaço, pois é sempre uma relação, mesmo que diferenciada, com outros atores." (Raffestin, 1993 apud RATTS, 1996).

Em seus trabalhos, Alecsandro Ratts $(1996,2003)$ desenvolve o escopo do conceito de territorialidade na dimensão da extensão da memória coletiva de cada grupo. Assim, na conceituação desenvolvida pelo autor, a territorialidade se estende por todos os lugares onde passa a memória do grupo, onde este fez sua trajetória ou seus antepassados cruzaram.

Tomando o território na acepção de espaço apropriado por um grupo, "concreta ou abstratamente pela representação" (RAFFESTIN, 1993), o território dos Caetano deve ser considerado para além desta área delimitada. (...). Quem deseja entender o território negro não pode se limitar ao desenho original de Conceição, e deve incluir esse território extenso que se fundamenta na memória, nos percursos dos antepassados. (RATTS, 1996, p. 115).

A inclusão metodológica da memória para compreensão do território é uma dimensão imprescindível. Porém, especialmente para o caso do Rosa - e, presume-se, genericamente para o caso das comunidades negras rurais em movimento político - uma outra dimensão de vital importância precisa ser acrescentada, aquelas das relações desenvolvidas pelas comunidades com outros atores sociais.

A terra é apenas um dos substratos a auto-representação dos Caetano, ou seja, do grupo e seu território. A territorialidade não consiste numa "simples ligação com o espaço" pois é sempre uma relação, mesmo que diferenciada, com ouros atores. A família, frente às mudanças, aos outros, e comportando diversas trajetórias, parece ser o componente que determina a auto-imagem do grupo e qualifica o espaço por sua presença. (Idem, loc. cit.)

No desdobramento que queremos elaborar aqui, territorialidade diz respeito, além dos caminhos percorridos e guardados na memória, além dos laços de parentesco, ou seja, além do "repertório de lugares"; as relações sociais consistentes desenvolvidas pelo grupo com outros atores sociais que lhes permitem uma espacialidade segura para além dos limites de seu território e o avanço da efetivação de sua cidadania. Em outro texto, Ratts assim sintetiza a questão: “(...) a noção de território excede a terra, os limites dos agrupamentos reconhecidos como indígenas, e incorpora marcos espaciais ligados às dinâmicas do parentesco, dos rituais, das migrações e da atuação política." (RATTS, mimeo).

Tal perspectiva não destoa das recomendações metodológicas já assentadas por Ratts (1996). O autor aponta que o "elastecimento do território (...) é um fenômeno cultural e [não 
só isso, também] político" (op. cit., p. 115). É na direção política que desenvolveremos aqui a extensão do território e da territorialidade do Rosa.

Desenvolveremos o escopo da territorialidade do Rosa nesta dimensão assinalada. Nosso foco será nas alianças sociais desenvolvidos pela comunidade Rosa, tanto aquelas de natureza puramente social, quanto aquelas no sentido de seu próprio fortalecimento político.

É importante contextualizar que este fortalecimento político somente se torna um valor no contexto dos processos vividos pelas comunidades quilombolas da Amazônia e do Brasil no início do século XXI, que englobam processos de afirmação étnica, de titulação do território, de conquista da educação e da saúde diferenciada, de efetivação de políticas públicas (de moradia, educacionais, de valorização e preservação do patrimônio cultural), e de luta contra o racismo e, mais recentemente no Amapá, de defesa do território contra invasores, tanto invasores individuais, quanto atividades econômicas de grande porte, como a monocultura e a mineração; contexto, diga-se de passagem, no qual estas comunidades têm de se relacionar e confrontar diretamente o Estado brasileiro, tanto na ameaça que este representa por vezes à sua integridade, quanto na luta pela efetivação de seus direitos étnicos.

\section{ALIANÇAS SOCIAIS E POLÍTICAS: A TERRITORIALIDADE PARA ALÉM DO VÍNCULO DIRETO COM O TERRITÓRIO}

Esta pesquisa se baseia na assunção de uma mudança radical na territorialidade do Rosa no início do século XXI. Mudanças na territorialidade da comunidade podem ser identificadas em diferentes momentos ao longo de sua história, porém a mudança posta em tela aqui é aquela de quando da autoidentificação desta comunidade, até então uma comunidade negra rural, como comunidade remanescente quilombola.

Antes de tratar desta mudança na territorialidade debido a sua autoidentificação como quilombola, tratarei brevemente, apenas a título de situação histórica, de uma significativa mudança na territorialidade da comunidade devido a mudanças na sociedade regional entre o início do século XX e início do século XXI.

Esta diferença na territorialidade, entre a fundação da comunidade e a época contemporânea, é expressa na fala de Maria Geralda Menezes:

Sobre o documento de 1900, ele, meu pai, sabia um pouco; eu acho que não muito, mas sabia. Porque no tempo daquele pessoal era tudo no atraso um pouco; no nosso tempo não, a gente já vai abrindo mais um pouquinho o olho. Já vai ficando mais um pouco inteligente; mas no tempo deles, eu acho que eles pensavam que não ia ter 
muda de nada, todo tempo ia ficar naquilo mesmo. Porque naquele tempo era pouco movimento, pouca gente, pra você olhar daqui e dizer lá vai um carro, você sentava o dia todo e não via um carro passar em cima da pista, era muito difícil, e hoje não, hoje você deita e levanta e carro não para de correr em cima da pista.

A resposta territorial e mental da comunidade à transformação histórica e espacial da região no período implica uma mudança significativa na territorialidade da comunidade. Além desta, uma condição material se insere também no processo recente de construção da territorialidade do Rosa.

Com a construção e o melhoramento da estrada BR-156, a comunidade ganhou maior mobilidade e certa visibilidade, para além do círculo de relações das outras comunidades negras das áreas do lago Curiaú e do rio Matapi. Com estas comunidades, as relações são de longa data e consolidadas por via de casamentos entre elas além de participações nas festas (SUPERTI e SILVA; 2017).

Uma territorialidade que se caracterizava basicamente por casamentos intercomunidades e participação nas festas, teve uma potencialidade de desenvolvimento que foi efetivamente realizada pelo grupo, numa direção até então pouco explorada, devido ao melhoramento de uma via terrestre entre a comunidade e a cidade de Macapá. Este fator material não explica a territorialidade do Rosa no início do século XXI, porém é condição para o desenvolvimento desta territorialidade tal como ocorreu.

Não somente esta mudança de contexto regional e esta alteração infraestrutural demandou alguma alteração na territorialidade. Neste início de século, a transformação mais significativa na territorialidade da comunidade se deu, o auto-identificar-se como uma comunidade étnica, a implicação disto na transformação da territorialidade do grupo, dada pelas novas condições da etnicidade e pelo processo político necessário de fazer efetivar seus direitos.

A territorialidade contemporânea do Rosa somente se compreende dentro do novo processo de territorialização do grupo, ou, se se preferir, dentro de seu movimento social pela garantia de sua cidadania e efetivação de seus direitos étnicos, incluso os territoriais.

Em seu processo de mobilização política por reconhecimento identitário, titulação do território e garantia de demais direitos étnicos, como saúde e educação, o Rosa viu-se na posição de fazer e estreitar relações de natureza política com os atores sociais locais, regionais, nacionais e internacionais, estatais e da sociedade civil que atuam no campo dos direitos étnicos quilombolas.

Este processo político protagonizado pela comunidade é o vetor central de seu processo de territorialização e explicação de sua territorialidade contemporânea. Lembrando 
que, no sentido aquí adotado, a territorialidade se expande pela dimensão da memória e pela dimensão da criação de alianças. Por razões de recorte do objeto de pesquisa para o recorte temporal do início do século XXI, a territorialidade que se desenvolve para além dos limites do espaço físico da comunidade pela dimensão da memória coletiva do grupo não será tema de análise neste trabalho; somente a territorialidade referente aos laços sociais contemporâneos criados pelo grupo. Sendo assim, a territorialidade que está sendo posta em análise é esta das alianças criadas pela comunidade com outros atores sociais.

\section{AS ALIANÇAS COMO EXPRESSÃO DA NOVA TERRITORIALIDADE}

Nos contextos multiétnicos de contato, a existência de comunidades tradicionais, indígenas e quilombolas tem - e sempre deve ter - caráter e substância profundamente política, sob pena de seu desparecimento. A mobilização política permanente torna-se cotidiano destas comunidades e exigência intrínseca feita elas pela sociedade nacional circundante.

Todas as alianças criadas pela comunidade do Rosa têm efeito direto ou indireto em sua mobilização e força política. Para fins analíticos, todavia, separamos as alianças de caráter estritamente político, daquelas fundamentalmente de outra natureza, sem esquecer que tem também seu efeito sobre a mobilização política do grupo.

\section{Alianças de natureza estritamente política}

Sobre as alianças de caráter estritamente político, temos a participação das lideranças do Rosa em assembleias políticas e deliberativas formadas por segmentos da sociedade civil no Amapá e na Amazônia, como as reuniões do Conselho Consultivo do Mosaico da Amazônia Oriental, bem como o Seminário de Áreas Protegidas do Escudo das Guianas SAPEG.

No âmbito das alianças precisa ser posto o acesso aos serviços de órgãos especializados no atendimento às comunidades quilombolas, como é o caso da Fundação Palmares, responsável dentre outras coisas pelo reconhecimento oficial e certificação da comunidade como remanescente quilombola; e o Instituto Nacional de Colonização e Reforma Agrária - INCRA, que no momento inicial da mobilização do grupo, teve papel decisivo na informação à comunidade quanto aos direitos quilombolas e ao processo de titulação. 
Dos órgãos do judiciário há uma hierarquização da proximidade destes órgãos ao Rosa. Como expresso na fala de Joelma Meneses:

Então eu digo: 'eu já sou cliente da Polícia Federal'. Então o delegado Alexandre já me conhece e daí quando eu quero alguma coisa já ligo para ele e ele já me da um norte do que eu preciso fazer. Daí ei já vou direto porque ele diz que com ele é mais rápido, porque o Ministério Público demora muito mais. A primeira vez que eu fiz a denúncia, por exemplo, demorou mais de um ano para me chamarem. Então, eu prefiro ir logo na Polícia Federal que é bem mais rápido. (Joelma Menezes in ALMEIDA e MARIN, 2014, p. 10).

Malgrado a competência dos órgãos seja atuar em defesa de direitos ameaçados, a responsividade de um é maior em relação ao outro, e isto aparece na avaliação do quilombo.

Ainda sobre órgãos públicos, a aliança com universidades na região fortalece a comunidade e ensejou eventos que foram potencializados politicamente pela comunidade.

A primeira destas alianças foi com a Universidade Federal do Amazonas, no Projeto Nova Cartografia Social da Amazônia. Tal parceria produziu o primeiro mapa da comunidade, em 2014. A realização da carta em si constitui elemento de ganho de capital político para a comunidade, na medida em que lhe é produzido um instrumento que incrementa o poder de legitimação da comunidade em seus posicionamentos públicos. Todavia, além disso, o evento de lançamento do mapa foi potencializado pela comunidade como ato político.

O evento de lançamento projetou a comunidade no cenário regional e de importante significado político. Este lançamento da carta foi realizado em dois eventos: um na sede da comunidade e outro na Assembleia Legislativa Estadual, em Macapá.

$\mathrm{Na}$ comunidade foram convidados representantes de órgãos estatais, prefeitura e governo do estado. Tendo realizado esta cerimônia na comunidade com a presença de representantes do Estado, a comunidade foi convidada a realizar uma cerimônia de lançamento também na Assembleia Legislativa. Nesta ocasião, a comunidade denunciou as invasões e conflitos decorrentes que estava sofrendo em seu território. A projeção alcançada por estas denúncias levou as autoridades a tomar medidas imediatamente em relação a tais conflitos.

Destaque deve ser dado portanto à potencialidade de incremento de força política da comunidade dada pelas alianças que desenvolve. A formação destas alianças da condição de possibilidade para ações políticas de maior envergadura, maior força e maior impacto político. 
Este tipo de parceria se dá igualmente com a Universidade Federal do Amapá, com sede em Macapá, através do Núcleo de Estudos Afro-Brasileiros - NEAB/UNIFAP.

No âmbito do Judiciário, tanto a Polícia Federal quanto o Ministério Público Federal precisam ser lidos como alianças, na medida em que são órgãos que são responsivos aos acionamentos que a comunidade faz a eles e a defesa dos direitos instituídos da comunidade.

Mais recentemente a aliança com um grupo artístico interessado na produção de um documentário sobre a comunidade significa uma ação política protagonizada em torno da visibilidade do grupo.

De caráter material-estrutural, temos a relação com uma empreiteira que tornou possível a construção das moradias. E além do seu trabalho como tal, cede gratuitamente os serviços de seu advogado para o Rosa quando este solicita.

\section{Alianças de natureza social e cultural}

As principais alianças de natureza social e cultural identificadas até agora se dão no nível das festas tradicionais e das expressões culturais, musicais e dançantes, locais. Trataremos aqui brevemente de três delas: o encontro dos tambores, o marabaixo e o batuque.

O encontro dos tambores é o primeiro esforço de reunião de todas as expressões artísticas e culturais das comunidades quilombolas do Amapá. A reunião se dá com a finalidade de reunir num único momento todas as expressões culturais das diferentes comunidades, e acaba por reunir nesse mesmo momento as próprias comunidades, que em sua totalidade não se encontram com tanta frequência, dadas as distâncias entre umas e outras e dificuldades de mobilidade na região.

O Encontro dos Tambores é fruto de uma discussão entre pessoas envolvidas com a cultura, que viram a necessidade de se criar um evento onde aglutinasse todas as comunidades afroamapaenses, objetivando o fortalecimento das manifestações praticadas nas comunidades rurais e urbanas, como o Batuque, o Marabaixo, o Sairé, a Zimba, o Samba, o Tambor de Crioula, Capoeira e as religiões de Matriz Africana (Umbanda e Candomblé). Sua realização é feita em torno do dia 20 de Novembro. (AMAPÁ, 2012, p. 18).

Estes momentos de reunião são importantes para o fortalecimento de uma consciência social quilombola, para aproximação de lideranças e juventudes, e para o debate de pautas políticas e de possíveis ações.

Foi em um destes encontros que a comunidade do Rosa articulou-se com outras comunidades quilombolas para realizar a mobilização de 2002, que durou uma semana, para 
impedir a ICOMI de depositar rejeito de manganês em seu território. Deste encontro eminentemente cultural foi elaborada, planejada e inicialmente executada uma ação política concreta e crucial naquele momento na história do Rosa.

O marabaixo como expressão cultural, com caráter festivo e identitário, promove relações sociais intensas e amplamente difundidas no espaço, de caráter celebrativo e emotivo. Todavia com uma ambivalência. A aliança feita no marabaixo expressa a identidade quilombola no Amapá, traz e distribui a marca distintiva do traço étnico.

O Marabaixo é hoje uma manifestação cultural popular afroamapaense, nascendo assim das diferentes etnias que foram transportadas de suas terras de origem para o Brasil. (...) O Marabaixo firma-se como manifestação cultural de matriz africana e homenageia o Divino Espírito Santo e a Santíssima Trindade, na cidade de Macapá, tem o seu ciclo iniciado no sábado de aleluia, no bairro de Santa Rita (Favea), e no domingo, no bairro do Laguinho, e segue um calendário próprio. (AMAPÁ, 2012, p.5).

Malgrado não seja sua finalidade explícita, o marabaixo atua como substrato social para aproximação, soerguimento e consolidação de relações e alianças de caráter político. Conforme se fazem as amizades e estreitamento de laços nas festas de marabaixo - que promovem essas identificações mais do que qualquer outra festa por conta de seu marcante conteúdo étnico -, se amplia e se fortalece a rede política formada pelo quilombo.

Sua expressividade é marcadamente étnica e tem enraizamento na memória da origem na África, da diáspora, do passado no escravismo e da luta por liberdade.

O Marabaixo é um ritmo de lamento que retrata a escravidão, saudade e representa o ritual de despedida, simbolizado pelo momento em que os negros passam pela árvore do esquecimento, o último contato com a mãe África. (AMAPÁ, 2012, p. 20)

São músicas que retratam o cotidiano, com o objetivo de crítica, agradecimento, lamentação, exaltação, além de narrar fatos do cotidiano das comunidades. (...) Historicamente, também lembra o lamento firme e vivaz de negros que cultivavam a esperança de voltar para o continente africano. (AMAPÁ, 2012, p. 13).

A consciência da afrodescendência e do passado na condição de escravidão estão em primeiro plano, pois, nesta expressão cultural, que acaba por ter como efeito também guardar e levar aos mais jovens esta memória.

Ritmo conduzido no instrumento chamado tambor de barril. "Instrumento originalmente usado em rituais da religião africana Yorubá, foi adaptado para vários ritmos brasileiros, tais como o Jongo, o Carimbó e o Samba de Roda. " (AMAPÁ, 2012, p. 15). Conservando sua autonomia estilística, é manifestação também do vínculo com o passado africano e diaspórico. 


\section{OS CONTORNOS DA TERRITORIALIDADE}

O processo de territorialização recente do Rosa, pela primeira vez como comunidade quilombola, é dependente do estabelecimento e efetivação de uma territorialidade nova. $\mathrm{O}$ objetivo desta territorialidade é a garantia efetiva da cidadania étnica da comunidade. Onde a espacialidade do grupo encontra limites para sua territorialização, é onde também os direitos do grupo são negados. Ou seja, os limites concretos à realização da territorialidade do Rosa, encontrados nos sujeitos sociais que sustentam interesses contrários aos direitos étnicos e territoriais do grupo, denotam os limites da territorialidade do Rosa no contexto regional e os obstáculos e desafios à sua territorialização.

No escopo da dimensão social das alianças que o grupo forma com outros atores, existe também o inverso das alianças, os adversários do grupo, contrários à efetivação de seus direitos, que não participam da territorialidade do grupo senão no sentido de constituir os limites desta territorialidade.

Nesse sentido, no período histórico analisado, o INCRA apareceu em dado momento como adversário do grupo e, portanto, uma limitação e obstáculo a sua territorialidade.

Assim Joelma Menezes se expressa sobre a demora no andamento do processo de titulação do quilombo:

\footnotetext{
Olha, uma coisa que eu sei é que esse processo passou dois anos engavetado, que na época desses dois anos o superintendente do INCRA era sobrinho de deputado estadual que é um dos maiores grileiros de terra do estado do Amapá. Então, para ele, isso não tinha interesse nenhum com relação a isso. E depois, veio aquele limosidade e aquela demora: 'Ah, é por conta que não encontra fulano'. 'Ah, porque o INCRA nunca tem transporte, nunca tem carro'. Então, sempre inventaram uma desculpa. Agora que a gente está indo lá; é que tem uma pessoa que está nos dando os mais detalhes. (Joelma Menezes in ALMEIDA e MARIN, 2014, p. 10).
}

O superintendente do INCRA e o deputado estadual que era seu vínculo, por compartilharem interesses na exploração econômica das terras do Amapá, incluso aquelas do Quilombo do Rosa, trabalhavam para impedir a efetivação dos direitos territoriais do Rosa sobre seu território de ocupação tradicional, o que impediria por sua vez a possibilidade de exploração econômica das terras do Rosa.

Na mesma linha, o Programa Terra Legal, programa de regularização fundiária liderado pelo governo do estado do Amapá, constituiu limitação à territorialidade e ameaça concreta ao território do grupo. Joelma Menezes narra o episódio de uma pessoa que entrou 
na comunidade e estava tentando regularizar terras do quilombo como se fossem suas, através do Programa Terra Legal.

Porque a pessoa que entrou lá era um paranaense. Era do Terra Legal, os documentos feitos pelo Terra Legal. Na verdade, eu acho que ele queria toda a área que era da AMCEL, porque o que ele fez foi uma casa no começo, outra no meio e outra no fim. Em toda a área. Então, ele estava demarcando todo aquele espaço como se fosse dele. (...) Esse senhor que entrou na área foi indiciado pela Polícia Federal. (Joelma Menezes in ALMEIDA e MARIN, 2014, p. 10-11).

A ameaça à territorialidade e ao território do grupo se dá no presente pela rede articulada em torno do agronegócio no estado. Nas palavras de Joelson Menezes:

Aí a gente precisa sempre estar tendo atenção, como é uma área, uma comunidade próxima da cidade, entendeu, tem lugar para plantar... E o que eles querem é plantar soja. Então área que tinha lá plantada pinhos da AMCEL, com certeza é que para plantar soja, milho, arroz, essas coisas assim. (Joelson Menezes in ALMEIDA e MARIN, 2014, p. 10-11).

Assim, a exploração anterior de pinho, por uma multinacional do ramo madeireiro, a estrada de ferro instalada por uma mutinacional da mineracao, e atualmente o interesse externo na plantação da soja, são ameaças ao território e limitações à territorialidade da comunidade.

A territorialidade se exprime numa forma de ser específica. Para a comunidade ser, em sua plenitude, é indispensável a efetivação de direitos. Pra ficar no básico, territorialidade não se plenifica sem infraestrutura material, educação, saúde.

Nós não temos nenhum benefício nem escola, nem nada. A gente corre atrás. Olha, para ter uma ideia, até os postes daqui que é para trocar, a gente já fez documento; (...) E, realmente, a gente vai ter que fazer um bingo para colocar os postes. E nós pagamos imposto. E não é barato, o que a gente paga. (Joelma Menezes in ALMEIDA e MARIN, 2014, p. 11).

Nossas crianças tem que ir na 'Escola de Campina Grande' ou de 'Torrão de Matapi' que ficam a uma distancia de 15 a $16 \mathrm{~km}$. (Jocilene Menezes in ALMEIDA e MARIN, 2014, p. 11).

A defesa do território, no contexto local do Rosa, deve passar também pela defesa contra o racismo ambiental.

O Quilombo do Rosa e o Quilombo do Curiaú se uniram pra impedir que a ICOMI fizesse depósitos de mais de 384 mil toneladas de rejeito tóxico em bacias cavadas no seu território, o que representou um processo político e judicial que se arrastou por anos, até as comunidades terem a vitória com a paralisação desta ação. (ALMEIDA e MARIN, 2014, p. 11).

Trata-se, como vemos, de uma luta contra racismo ambiental. Uma luta também, permanente. 


\section{CONSIDERAÇÕES FINAIS}

O processo de territorialização recente do Rosa, pela primeira vez como comunidade quilombola, é dependente do estabelecimento e efetivação de uma territorialidade nova. A razão de ser desta territorialidade é a garantia efetiva da cidadania étnica da comunidade, ou seja, o sucesso da territorialização do grupo.

$\mathrm{Na}$ territorialidade do Rosa, temos alianças de caráter político propriamente dito, de caráter festivo-emotivo-identitário, de caráter material-econômico. A criação dessa rede de relações em diferentes direções e dimensões da realidade social, com centralidade e protagonismo - às vezes compartilhado - no próprio grupo testemunham o escopo amplo e a natureza multifacetada da territorialidade do grupo.

A territorialidade, asssim, se estende para muito além das terras da comunidade, englobando todos os atores que, no contexto multiétnico de contato, alia-se a comunidade e trabalha pela efetivação das cidadanias étnicas.

No caso do Rosa, um novo processo de territorialização implica e demanda uma nova territorialidade; e como a efetivação desta nova territorialidade é condição para o sucesso da nova territorialização.

Destaque deve ser dado, portanto, potencialidade de incremento de força política da comunidade dada pelas alianças que desenvolve. A formação destas alianças dá condição de possibilidade para ações políticas de maior envergadura, maior força e maior impacto político.

Estender a dimensão da territorialidade aos laços sociais que atuam no intento de garantir os direitos étnicos do grupo não é equivocado, quando, em se tratando do estado democrático de direito, a sociedade com a qual este grupo tem de lidar, ou seja, aquela que forma com ele uma relação intercultural ou um contexto multiétnico de contato, é na forma da universalização dos direitos humanos e da garantia e efetivação dos direitos étnicos que se pode realizar plenamente o ser e o vir-a-ser de cada grupo étnico. Em resumo, entender assim a nova territorialidade criada pelo grupo tem por razão de ser a sustentação de seu novo processo de territorialização. Este é o motivo daquela; aquela o veículo deste. 


\section{REFERÊNCIAS}

ALMEIDA, Alfredo Wagner Berno; MARIN, Rosa Acevedo (coords.). Mapeamento social como instrumento de gestão territorial contra o desmatamento e a devastação: processo de capacitação de povos e comunidades tradicionais. Associação de Moradores e Produtores do a Comunidade Remanescente de Quilombolas do Rosa, Amapá. Manaus: UEA Edições, 2014. 12p.

AMAPÁ. Tambores no meio do mundo. O rufar da cidadania. Macapá: Governo do Estado do Amapá, 2012.

FIGUEROA, Alba Lucy Giraldo. Relatório antropológico sobre a comunidade de remanescentes do Quilombo do Rosa, município de Macapá, Amapá. Brasília: INCRABSB/DFQ, 2007.

HAESBAERT. Rogério. O mito da desterritorialização: do "'fim dos territórios" à multiterritorialidade. Rio de Janeiro: Bertrand Brasil, 2004.

Da desterritorialização à multiterritorialidade. Anais do X Encontro de Geógrafos da América Latina. Universidade São Paulo. 20 a 26 de março de 2005. pp. 6774-6792.

RATTS, Alecsandro. Conceição dos Caetano: memória coletiva e território negro. Palmares em Revista. Brasília. n. 1, 1996, p. 97-115.

(Re)conhecer quilombos no território brasileiro: estudos e mobilizações. In:

FONSECA, Maria Nazareth Soares (Org.). Brasil Afro-Brasileiro. Belo Horizonte: Autêntica, 2000, p.307-26.

. A geografia entre as aldeias e os quilombos: territórios etnicamente diferenciados. In: ALMEIDA, Maria Geralda de \& RATTS, Alecsandro JP. (Orgs.). Geografia: Leituras Culturais. Goiânia: Editora Alternativa, 2003, v. 1, p. 29-48.

. Almofala dos Tremembé: a configuração de um território indígena. Mimeo.

SAHLINS, Marshall. Goodbye to Tristes Tropes: Ethnography in the Context of Modern World History. The Journal of Modern History, vol. 65, nº. 1, (Mar., 1993), 1-25. 
SOUZA, Marcelo Lopes. Os conceitos fundamentais da pesquisa sócio-espacial. Rio de Janeiro: Bertrand Brasil, 2013.

SUPERTI, Eliane; SILVA, Gutemberg Vilhena. Mapeamento e publicação do patrimônio cultural das 28 comunidades quilombolas no estado do Amapá, certificadas e/ou tituladas pela Fundação Cultural Palmares. 2013. Disponível em:

http://comunidades.lides.unifap.br. Acesso em 1 de Novembro de 2017. 